\title{
Determinación del trazado histórico y evolución de la antigua muralla de Calp, tras el análisis de la documentación gráfica y documental existente
}

\author{
Anna Delcampo Carda ${ }^{a}$, Ana María Torres Barchino ${ }^{b}$ y Ángela García Codoñer
}

Instituto Universitario de Restauración del Patrimonio, Universitat Politècnica de València, Valencia, España,

aandelcar@upv.es, batorresb@ega.upv.es, ${ }^{\mathrm{c}}$ angarcia@ega.upv.es

\begin{abstract}
With the passing of years and in this period of profound change at the turn of the century, historical centres of our cities and their society have undergone alterations of several natures. Calp is a Mediterranean city located in Alicante, and it is a perfect example of this fact: Its historical centre has a characteristic double historical fortification, but nowadays, it has basically disappeared. The present study is based on the compilation, comprehension and analysis of the collected information, such as historical documents, cartographies, photographies, etc. with the goal of generate a graphical production of the development of the Calp historical double fortification and its disappearance ${ }^{1}$.
\end{abstract}

Keywords: Historical Centre, fortification, historical cartographies, Calp.

\section{Introducción}

Calp $^{2}$ es un municipio de la Comunidad Valenciana (España) situado en la costa norte de la provincia de Alicante, en la comarca de la Marina Alta, Partido Judicial de Denia (Fig.1).

El topónimo responde a una de las poblaciones más antiguas de la provincia de Alicante, quedando en ésta restos de las diferentes culturas y sociedades que en ella se establecieron y en la que gracias a su privilegiada y estratégica situación geográfica en la costa, junto con el característico y apacible clima mediterráneo, se convirtió en un entorno óptimo para el desarrollo de diferentes episodios históricos (López, 2010). Tradicionalmente, Calp fue una población agrícola; su economía también se apoyaba en la pesca y la extracción de sal de sus salinas, hoy en día convertido en parque natural. A partir del año 1960, se convierte en un municipio turístico, viéndose alterada su economía y urbanismo mediante la construcción de chalets y hoteles, modificándose su fisionomía, y transformándose en la ciudad que conocemos hoy en día.

\section{1. Ámbito de aplicación}

La delimitación del área de estudio coincide con el ámbito conocido como Casco Histórico de Calp, definido en el plano de ordenación del Casco Urbano perteneciente al Plan de Ordenación Urbana de Calp.

Éste recoge el nacimiento del municipio con una trama urbana que deja entrever numerosos vestigios de cada época histórica, caracterizado por su trazado irregular debido al doble recinto amurallado y que a continuación pasaremos a analizar.

\section{Objeto}

Los orígenes de la ciudad de Calp -datados a mediados del siglo XIV- se marcaron por su 
singular doble recinto amurallado muy característico. Actualmente, esta fortificación se presenta prácticamente inexistente. Su casco histórico es, en la actualidad, la síntesis de los diferentes pueblos y culturas que lo han ocupado. Es por ello, que se hace necesario proceder a una recopilación de toda la documentación existente -tanto bibliográfica, urbanística, cartográfica, fotográfica y gráfica, entre otras- y que hasta ahora aparece un tanto disgregada e inconexa en diversas fuentes de información, para volver a remontar cada una de estas piezas hasta poder reconfigurar las trazas arquitectónicas y urbanísticas de la evolución de la ciudad de Calp y su recinto amurallado. Para ello, ha sido necesaria la organización de toda la búsqueda de información documental con la correspondiente datación y análisis de cada una de las referencias más relevantes, obteniéndose, finalmente, la representación gráfica de una detallada evolución histórica.
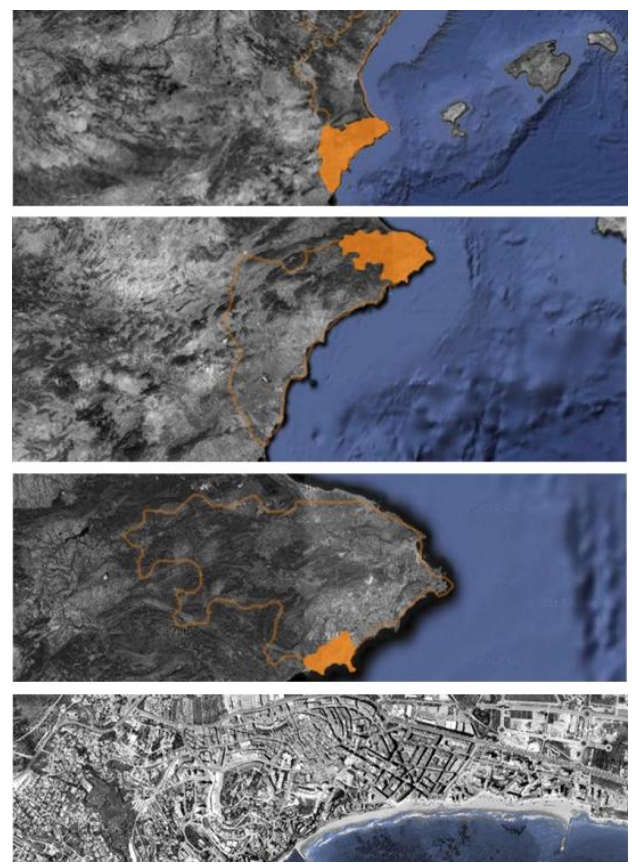

Fig. 1- Municipio de Calp, la Marina Alta, Alicante, Comunidad Valenciana, España

\subsection{Fuentes materiales}

Gran parte de este estudio se fundamenta en la materialidad del objeto, es decir, el centro histórico de Calp como hecho arquitectónico y ejemplo a tratar, plasmándose el análisis a partir de las diferentes técnicas de expresión formal y gráfica, levantamientos planimétricos, fotográficos entre otras. Destacaremos las numerosas visitas al centro histórico, tanto para realizar el reportaje fotográfico, como para conocer los edificios, sus calles y proceder a la toma de datos que ha sido utilizada en el trabajo. También nos hemos puesto en contacto con el arquitecto de la ciudad, así como con la Agente de Desarrollo Local de Calp, los cuales nos han confirmado la escasa información existente acerca de su centro histórico, y con Andrés Ortolá, experto de la sociedad histórica Calpina (premi 9 d'Octubre de Cultura 2011). Éste nos informó sobre la inexistencia de un archivo histórico en Calp, pues, durante la guerra civil fueron quemados. También hemos ido al Archivo Histórico Municipal de Valencia para obtener información original sobre el tema, sin embargo, dicha información ha sido bien escasa.

\subsection{Fuentes escritas}

Para alcanzar las metas mencionadas, el estudio se basa, en primer lugar, en la recopilación de las fuentes escritas tanto bibliográficas como archivísticas. Generalmente éstas corresponden con el formato del libro, revista, documentos antiguos e información obtenida en la "nube" a través de internet. Se ha obtenido el siguiente resumen acerca del recinto amurallado de Calp:

I. Nacimiento de Calp, siglo XIV: El presente análisis de la evolución de la ciudad se inicia a partir del año 1359, después de la destrucción del poblado de Ifac, cuando los habitantes se refugiaron en la cercana alquería de Calp, situada en el cerro cercano a la costa desde el que se dominaba la bahía. Este hecho permitió el despegue demográfico y económico de esta alquería, poniendo las bases para su futura consolidación como emplazamiento de la capitalidad del término ${ }^{3}$. Es en ese momento cuando nace Calp como lo conocemos hoy en día.

El núcleo urbano fue amurallado en la llamada "ciudadella". Las primeras noticias que se poseen documentadas, son proporcionadas por 
Jaume Pastor Fluixá en su libro "Historia de Calp" (1988), pues hace referencia al rey Pere IV cuando en 1338 ordena reforzar las murallas existentes. Pero, es Alfons el Vell el que decide en 1375 que las rentas recogidas se destinen a "obrar e enfortir lo mur de dit lloch" y en 1376 finalmente se reparan. Sin embargo, la traza de la ciudadela data del Siglo XV. Las murallas estaban construidas en mampostería y dotadas de aspilleras ${ }^{4}$. A su vez, el Plan General Vigente de Calp en su "Breve descripción del desarrollo urbano de Calp" (1998), describe cómo eran los elementos defensivos, como los torreones cilíndricos de base, generalmente, troncocónica y un lienzo de la muralla de altura entre 5,30 y 7 metros y de un espesor medio de $70 \mathrm{~cm}$. Las viviendas se levantaron apoyando su fachada posterior en las murallas. En 1577, en el centro del recinto, se levanta un nuevo elemento defensivo, se añaden garitas en la muralla y se reforma la torre existente en el centro de la ciudadela llamada "El Macho", es decir, una torre de planta rectangular y con base en forma troncopiramidal.(VV.AA, 1998)

II. Calp, siglo XVII, los arrabales: En 1637 la Villa contaba con 18 casas intramuros y unos 350 habitantes. El acceso a la ciudadela se realizaba por su extremo sudoeste. Este acceso recibió el nombre de "El Portalet". El crecimiento demográfico de la villa durante este siglo había obligado a la población a residir extramuros, consolidándose dos arrabales. (VV.AA, 1998)

III. Calp, siglo XVIII, las invasiones: Con la ciudad creciendo, Calp sufre episodios de saqueos puntuales. Es de destacar, el escrito que el alcalde de Calp hace llegar al Duque de Caylús, Gobernador de Valencia informándole sobre los hechos acaecidos en la mañana del día 22, de invasión mora, el 28 de Octubre de 1744 un pequeño extracto transcrito:

“...la cercaron con un fuerte cordón, y plantando dichas vanderas a modo de triangulo, y a correspondientes distancias desfilaron a la Puerta de la Villa y Murallas, y encontrando resistencia dentro (...) no pudiendo entrar en la Villa, se destacaron a los Almahacenes y Arrabales, que havian quedado sin Persona alguna, y rompiendo, y descerrajando Puertas, se apoderaron de ellos, saqueando cuanto encontraron, y quemando hasta doce casas, y aún las Cavalleria, (...) Y continuando los del cordón con el tema de querer entrar en la Villa, jamas lo pudieron conseguir, (...) la defendieron con gran valor, matando muchos turcos, así con los Fusiles como con las Piedras que las dejavan caer de las Murallas... ,5

Se observa cómo, tras la invasión, los arrabales del pueblo son vastamente destrozados y saqueados. Sin embargo, los invasores no llegan a entrar en la Villa, manteniéndose su estado.

IV. Nuevo recinto amurallado, siglo XVIII: Como muestra el siguiente extracto sobre algunas partes del presupuesto, es a raíz de este suceso, cuando el Marqués de la Ensenada inicia una serie de gestiones que darían como resultado una nueva fortificación, entre los años 1745-47:

"Recinto antiguo de la Villa necessita, la muralla, un revestimiento, en toda ella; tanto en la parte exterior, como en la interior, de mamposteria ordinaria, al precio de 150 R.v, la tuesa cúbica..Total 322 R.v.Coronación superior de la pared; que ha de formar todas las espilleras, (...) recinto también de mamposteria ordinaria. Ydem parta la reedificación del Torreón arruinado=todo masiso de mamposteria ordinaria.Ydem para una puerta nueva al recinto de la Villa (...)Ydem para dos puertas nuevas a la entrada de los arrabales de ocho pies de alto; y seis pies de ancho de misma calidad, y con su herraje correspondiente." 6 (Fig. 2)

En 1746, es conocida la primera cartografía de Calp: entre 1746 y 1747, se redactaron varios proyectos para dotar a la villa de un nuevo recinto amurallado redactados por el ingeniero Nicolas Bodin y modificados por el también ingeniero Carlos Desnaux, el cual había sufrido varias modificaciones debido al coste $\mathrm{y}$ a las dificultades del terreno. Las obras ejecutadas fueron: Reparación de las murallas y cambio de la puerta de "El Portalet" y construcción de un muro que cercara los arrabales. Este recinto tendría dos puertas. Calp completaba así su fortificación con un doble cinturón de murallas 
que rodeaba definitivamente la ciudadela primitiva y los arrabales (VV.AA, 1998).

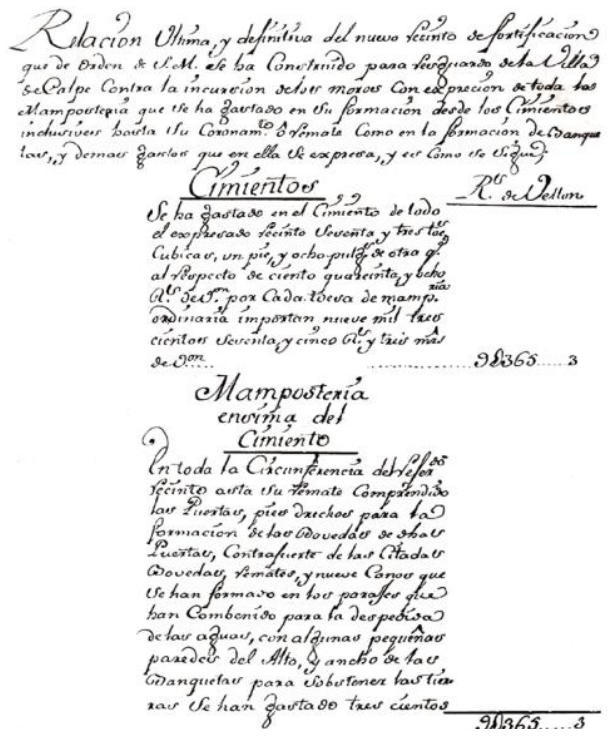

Fig. 2- Originales de los documentos con el coste de la obra. Calpe, 24-10-1747 Fuente: http://.historiadecalp.net, (05/2013)

Las murallas de la Villa sufrieron diversas reparaciones y reformas, siendo la más significativa la de dotar al extremo sudeste de la ciudadela de un baluarte de planta pentagonal denominado "la Peça", que se edificó sobre el que existía con anterioridad. A modo de curiosidad, cabe destacar que los baluartes se dispusieron oblicuamente, para evitar afrontar de plano la posible trayectoria de los disparos, en caso de invasión o saqueo. Se observa que también se proceden a hacer reformas. Las obras se realizarían mediante mampostería y se accedería a través de las dos puertas ${ }^{7}$. Es también en este siglo, en el año 1792, cuando A. J. Cavanilles, botánico que recorrería España para examinar los vegetales que en ella crecen, visita Calp, dejándonos referencias al respecto. Se presenta un extracto de la transcripción:

"Segui hacia Calp, villa de 237 vecinos, pisando un suelo árido y estéril, donde crecen arenarias, llantenes, ondnides, y otros vegetales; la población está sobre una loma á 200 varas del mar: los edificios demuestran la pobreza de sus moradores, poco aplicados á la agricultura, y casi privados de propiedad, que pertenece á varios de Benisa. (...)se dedican á la pesca, y no pocos al contrabando; vicio común en aquellas costas, que fomenta la abundancia de calas mal resguardadas, y la aspereza de los montes (...)"

V. Calp, siglo XIX, expansión occidental: Durante este siglo la villa se desarrolla hacia occidente. El eje básico de crecimiento es la traza del camino hacia Altea y Alicante. La calle Mayor se convierte en el eje vertebrador del ensanche occidental. El desarrollo del arrabal norte de la ciudad es tardío. Primero se procedió a edificar casas adosadas a la muralla (VV.AA, 1998). Ya en 1837 y en plena guerra carlista, según revela la revista "Calp Història" (2008), la comandancia de Armas del distrito promueve la recomposición del recinto fortificado. Iniciándose en 1838, se realizan trabajos de remozado de murallas, llevadas a cabo a través de las contribuciones los pueblos circundantes:

"Apurándome las circunstancias como sucede de cada día por la aproximación de las facciones, llegaremos al caso crítico de haber de abandonar esta villa, dejándola expuesta al pillaje y al asesinato de las hordas del pretendiente si intentan penetrar en esta"

Es también Pacual Madoz, en su "Diccionario", quien en 1845 describe Calp manifestando:

"CALPE. Villa con ayuntamiento de la provincia de Alicant, aud. Terr., c. g. y dióc. De Valencia (15) : situado en una loma a 800 palmos del mar, (...), y por las que se detienen en el terreno que ocupaban unas antiguas salinas, secas hoy. Tiene sobre 300 casas de no muy buena fábrica y pobre aspecto, casa de ayuntamiento, cárcel muy mezquina; una escuela de primeras letras, á la que concurren 30 niños, dotada con 2.000 rs., y una iglesia (...) Esta villa está fortificada por dos muros antiguos; el primero de los cuales circuye todo el casco de la población, menos el arrabal, y el segundo se halla situado en el centro del pueblo con 3 fuertes de batería. (...) Es enteramente calizo, en parte de mármol blanquecino. Crecen muchisimas plantas..." (Madoz, 1845) (Fig.3). 

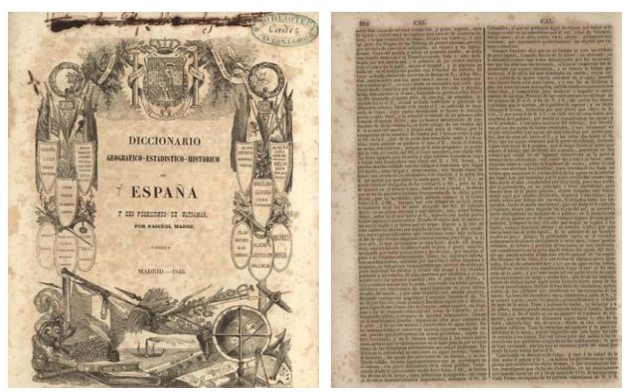

Fig. 3- Comentario de Calp. MADOZ, P. 1845. "Diccionario geográfico-estadístico-histórico de España y sus posesiones de ultramar”. Madrid

Como se observa, tanto Cavanilles como Madoz insinúan en sus textos la "pobreza" de los Calp en esos años. Como continúa indicando la "Breve descripción del desarrollo urbano de Calp" en su Plan General Vigente (1998), a finales del siglo XIX, siguiendo las corrientes higienistas de la época, se procede al derribo de parte de los lienzos de muralla, creándose dos espacios públicos que articulan la trama urbana Hacia 1870 las murallas calpinas comienzan a perder sentido como elemento defensivo. La propia expansión urbana precisaba eliminar esta fortificación que estrangulaba su desarrollo ante la población creciente. Años más tarde, partes de la muralla son eliminadas, y con ellas los bancos de tierra adosados al muro, nuevos solares que se harían efectivos utilizándose los lienzos de muralla como medianeras o fachadas, rebajándose hasta la altura de la misma, y usándose los materiales para la edificación de nuevas viviendas. (VV.AA, 1998).

VI. Crecimiento urbano, siglo XX: Durante el primer tercio se consolida el proceso de crecimiento de la Villa hacia occidente, y durante los años cuarenta el camino del Mar comienza a definirse por la edificación. Del segundo cinturón de muralla no queda nada, sólo unos pocos trozos en algunos patios de las calles José Antonio, Mar y Purísima. Hay que esperar a los años treinta para que se inicie el despegue del eje costero de la Villa, con sus consiguientes construcciones hoteleras. Durante la segunda mitad de la década de los sesenta tiene lugar el gran auge de la construcción provocado por la expansión del fenómeno del turismo, que ha trasformado el municipio en la ciudad turística actual (VV.AA, 1998).

\subsection{Fuentes Cartográficas}

Se procede también a la búsqueda de toda la información cartográfica existente, gracias a las cuales se puede hacer posible la visualización tras la evolución descrita a través de fuentes escritas. A pesar de ser bien escasa, podemos obtener una idea gráfica de la Villa y su desarrollo: La primera cartografía conservada y documentada de la ciudad de Calp (Fig.4), data del año 1745; se observan los arrabales dispuestos extramuros de la Villa. Podemos reconocer la disposición de la Iglesia y la torre "El Macho", que parece amenazar ruina. En alzado, se muestra cómo era este elemento defensivo, así como "El Portalet". Además, se conoce la existencia de 21 casas dispuestas en la Villa y 113 casas en sus arrabales.

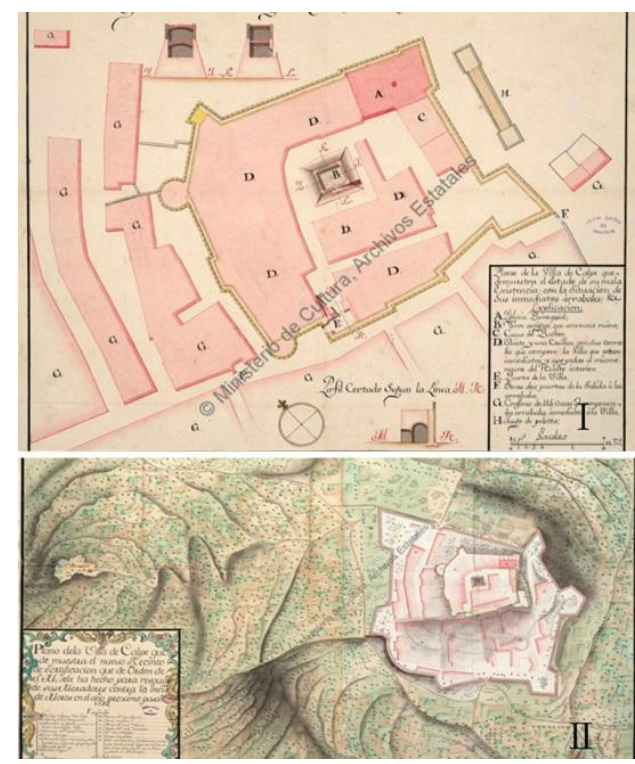

Fig. 4- I. "Plano de la villa de Calpe que demuestra el estado de su mala existencia, con la situación de sus inmediatos arrabales",1745, de Agustín Bodin Nicolás. II: "Plano de la villa de Calpe que demuestra el nuevo Recinto de Fortificación (...) contra la incurción de Moros en el año próximo pasado 1747”, de Carlos Desnaux. Origen: Catálogo Colectivo de la Red de Bibliotecas de los Archivos Estatales. 
Existen cartografías de los años 1746, 1747 y 1748 donde se visualizan detalles constructivos de la fortificación, hasta ahora desconocidos, así como el doble recinto amurallado (Fig.4) y donde se reconoce el paralelismo con el estudio de las fuentes escritas. Se aportan nuevas informaciones, detalles y curiosidades, como las diversas propuestas diseñadas para la ejecución del segundo recinto, presentes en diversas cartografías, como las dibujadas por Carlos Desnaux en 1746; planos como los de Coello, en el año 1859 donde se mantienen todavía las murallas y se observan inicios de expansión, así como el plano dibujado por el cura del pueblo, en 1942 (Fig.5), donde aparece todavía la calle de las Nieves sin la torre de "El Macho" y la Villa mantiene las dos plazas. También encontramos el "muro viejo", es decir, parte de la antigua muralla del primer recinto. "La Peça", aparece situada en una disposición diferente a la original, deduciéndose que fue restaurada y trasladada a dicha zona posteriormente. Se ratifica de forma gráfica el avance y deterioro de las murallas. Se finaliza el análisis con planos más actuales, como el "Mapa Topográfico Nacional de España. Calp 1996", entre otros, donde se observa Calp tal y como es hoy en día.

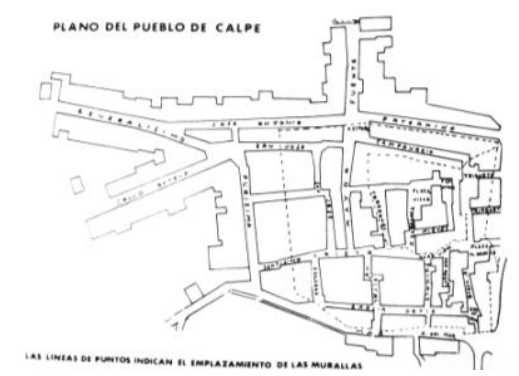

Fig. 5- "Casco Antiguo de Calp", de V. Llopis. Origen: LLOPIS, V. 1942 (1ed). Aj. de Calp

\subsection{Fuentes Fotográficas}

Se considera imprescindible la revisión del fondo fotográfico histórico existente de Calp, con el objetivo de hallar datos o detalles que mediante las otras fuentes no ha resultado posible encontrar. De este modo, encontramos fotografías donde aparecen construcciones que hoy en día ya no existen, como el originario edificio del Portalet, o fotografías aéreas antiguas que pueden mostrarnos cómo era Calp, antes del auge de la construcción, como es el caso de la Fig. 6, datada en 1956, donde, realizando un zoom al casco histórico, se observa cómo la av. Altea y Gabriel Miró han sufrido un fuerte desarrollo, convirtiéndose en dos ejes vertebradores. Además, su fisionomía se ve modificada debido a nuevas construcciones y la ausencia de torre de "El Macho", desconociendo la fecha exacta de su demolición. Otras vistas aéreas e imágenes nos muestran los restos originales de las murallas y baluartes y zonas actualmente desaparecidas.

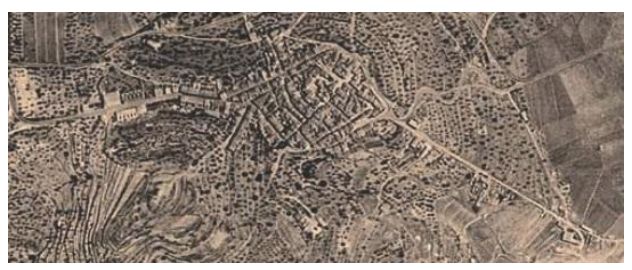

Fig. 6- "Vuelo Americano", Calp, Junio 1956. Origen: Butlletí Calp, ${ }^{\circ} 1$. Ajuntament de Calp. Institut d'Estudis Calpins

\subsection{Otras fuentes}

Un análisis de la documentación a través de las posibles imágenes existentes es necesario, en aras a obtener información que por otros medios no hemos podido encontrar. Por ejemplo, el Ayuntamiento de Calp ofrece una idealización tridimensional del primer recinto amurallado de Calp del siglo XVII donde se observa la Torre "El Macho" y cómo las diversas casas se apoyan en el lienzo de muralla. En el libro "Historia ilustrada de Calp" (Fig.7) encontramos la representación de esta torre.
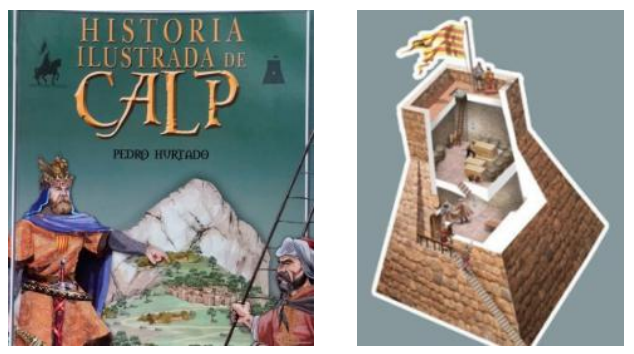

Fig. 7- "Torre El Macho". Origen: Hurtado, P. 2011. "Historia Ilustrada de Calp". Ayunt. Calp. 


\section{Conclusiones}

Recopilar las informaciones -tanto documentales como gráficas- que aparecen hasta ahora un tanto disgregadas e inconexas en diversas fuentes de información, volver a remontar cada una de estas piezas hasta poder reconfigurar las trazas arquitectónicas y urbanísticas de la evolución de la ciudad de Calp, es el objetivo de este último apartado. Con toda la búsqueda de información realizada, y datadas cada una de las referencias más relevantes para nuestra investigación, hemos obtenido una posible evolución, resumiéndose del siguiente modo (Fig.8 y 9):

1 s XIV - s XV. Núcleo urbano "Ciudadela" amurallada, primer recinto. Acceso sudoeste "El Portalet". Elemento central defensivo "El Macho". 18 casas intramuros -350 habitantes.

2 s XVII. Arrabales. 21 casas intramuros, 113 arrabales

3- Mediados s XVIII. Nuevo recinto amurallado. Dos accesos - puerta del mar- Puchalt y Plaza del Mosquit -Altea Baluarte "La Peça". Levantamiento Ermita San Salvador, extramuros. 237 vecinos

4- Principios s XIX. Calle Mayor -eje vertebrador del ensanche occidental. Crecimiento calle Libertad, calle de Fora y calle Ermita. Definición c/ Campanar y c/ de la Justicia. 300 casas

5- Mediados s XIX. Derribo parte de las murallas para generar dos espacios públicos que articulan trama urbana -Plaza del Mosquit y Plaza de España. No existe "El Macho"

6- Principios s XX. Murallas pierden su función -se convierten en medianeras de nuevas casas. Edificación solares eje carretera Altea. Desarrollo Calle de la Font -1er depósito agua potable

7- s XX. Derribo de "El Portalet". Derribo de "La Peça". Proceso de renovación edilicia en el Centro Histórico. Nuevo templo parroquial en la ciudadela. Fenómeno de la construcción -gran auge

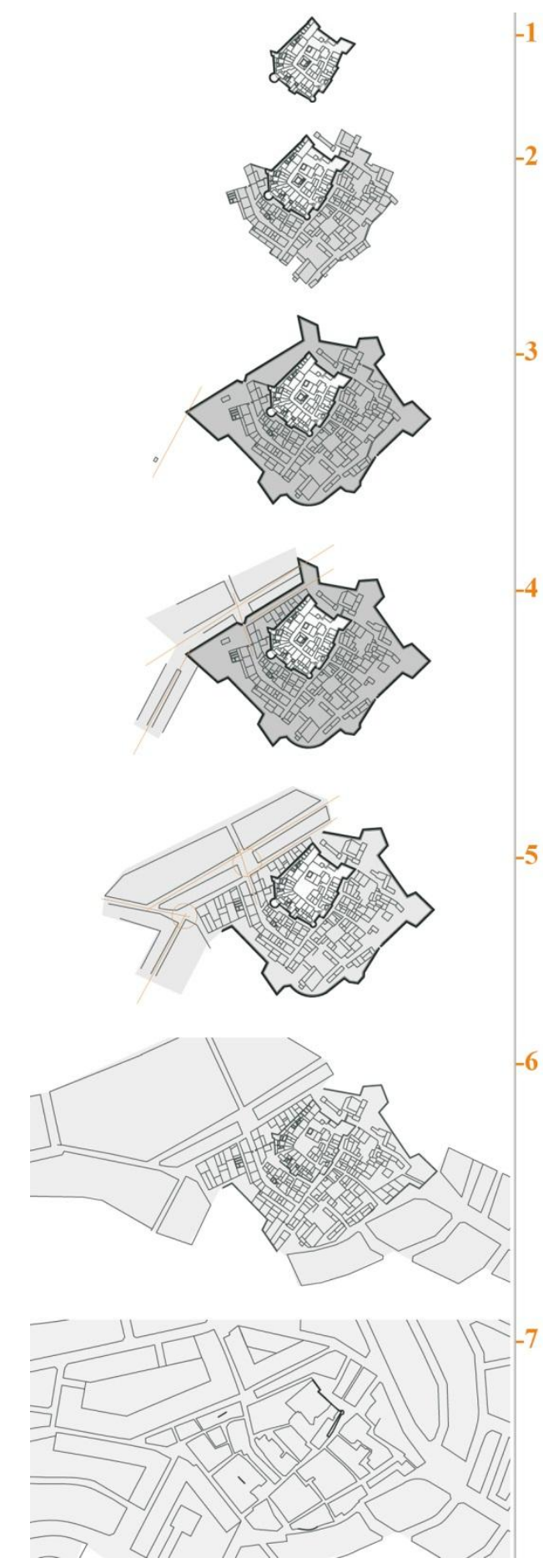

Fig. 8- Evolución del Centro Histórico de Calp. Elaboración propia 

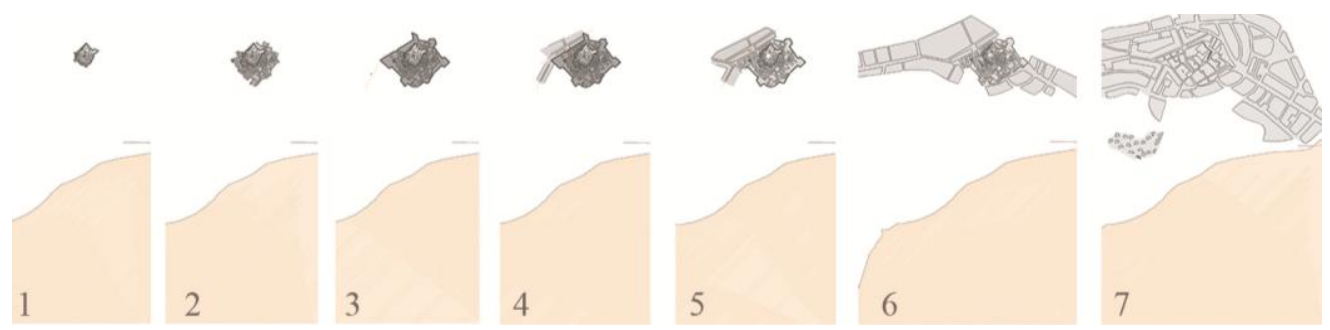

Fig. 9- Evolución ciudad de Calp. Elaboración propia

Como se observa, en la trama urbana quedan numerosos vestigios de cada época histórica que el plano nos permite reconocer. A partir de la lectura del mismo, y gracias al conocimiento establecido acerca de la evolución de este centro histórico podemos averiguar cuáles han sido las distintas etapas de su crecimiento.

Los espacios generados tras el derribo de las fortificaciones, conectados entre sí, forman un peculiar paisaje urbano: Calles, callejones, plazas, plazuelas, parques o escalinatas son ejemplos de esto, generados gracias a una evolución de la ciudad, que paso a paso ha ido contando su historia hasta nuestros días.

\section{Notas}

${ }^{1}$ El presente artículo forma parte del Trabajo Final de Máster realizado por Anna Delcampo Carda, con el título "El concepto de Paisaje Urbano Histórico en la conservación del patrimonio. Una propuesta metodológica: El ejemplo del Centro histórico de Calp".

Directoras de Tesis: Ana $\mathrm{M}^{\mathrm{a}}$ Torres Barchino y Ángela García Codoñer. 2013

${ }^{2}$ Calp, que significa en fenicio "ánfora boca abajo"

${ }^{3}$ Regidoria de Medi Ambient i Serveis Tècnics. Ajuntament de Calp

4 Aspillera, tal y como describe la RAE, "Abertura larga y estrecha en un muro para disparar por ella"

${ }^{5}$ Transcripción del escrito del Alcalde de Calp al Duque de Caylús, Gobernador de Valencia. 1744. http://historiadecalp.net (05/2013)

${ }^{6}$ Presupuesto enviado por el Marqués de la Ensenada sobre las nuevas obras del recinto amurallado. 1745. http://historiadecalp.net $(05 / 2013)$

${ }^{7}$ Extracto del documento de Coste de la Nueva fortificación y reformas de Calp. 1747. http://historiadecalp.net (05/2013)

\section{Referencias}

Cavanilles, A. J. (1797). Observaciones sobre la Historia Natural, Geografía, Agricultura. Imprenta Real. Madrid.

Hurtado, P. (2011). Historia Ilustrada de Calp. Ajuntament de Calp.

Llopis, V. (1975) (4 ed). Calpe. Ajuntament de Calp. Concejalía de Cultura. Calp.

López García, J.P. (2010) Calpe recuerdos de otros tiempos”. Calp.

Madoz, P. (1845) Diccionario geográfico-estadístico-histórico de España y sus posesiones de Ultramar. Madrid.

Pastor I Fluixà, J. (2005) Les Baronies de Calp, Benissa, Teulada i Altea. Ajuntament de Calp. Generalitat valenciana. Biblioteca valenciana.

VV.AA. (1998) "Breve descripción del desarrollo urbano de Calp", en Catálogo de elementos y edificios protegidos de Calp. Plan General Vigente.

VV.AA. (2008) Revista Calp Història. 2008. Num 1. Institut d'Estudins Calpins. Ajuntament de Calp. VV.AA. (2009) Butlletí Calp. Institut d'Estudins Calpins. Ajuntament de Calp.

http://historiadecalp.net 